\title{
DISSECTING ANEURYSM OF THE INTERVENTRICULAR SEPTUM*
}

\author{
BY \\ A. A. FITZGERALD PEEL \\ From the Cardiac Department, Victoria Infirmary, Glasgow
}

Received July 22, 1948

Bernheim $(1910,1915)$ first drew attention to the occurrence of right heart failure as a result of mechanical obstruction produced by bulging of a hypertrophied interventricular septum into the right ventricle. A number of cases were later described by French and by Latin-American writers (Laubry, 1924; Martini and Joselwick, 1927; Bullrich, 1927 and 1928; Patiro-Mayer and Mazzei, 1928). Until recently, however, the condition has received little attention elsewhere. Fishberg (1937) refers to it in his book on heart failure; Glushein and Geer (1944) report one case; and Russek and Zohman (1945) describe three, of which two were diagnosed during life. The usual cause is hypertrophy of the septum occurring as an integral part of concentric left ventricular hypertrophy in cases of hypertension or aortic valvular disease. The diagnosis can be made clinically. where isolated right ventricular failure develops with a lesion that ordinarily causes left ventricular or combined failure.

Rupture of the interventricular septum is an occasional sequel of coronary occlusion. Wood (1944) found thirty-eight reported cases of which eight were diagnosed during life. Rupture generally took place between the third and twelfth days. The onset was associated with substernal pain and shock, followed by appearance of a murmur and thrill. Cyanosis and dyspnœa were present in all reported cases except that of Wood herself, and death commonly resulted from right ventricular failure. Only seven patients lived longer than four weeks, though one survived for four years and ten months.

The present case differs from those in Wood's series in that the rupture of the interventricular septum was incomplete. A dissecting aneurysm developed in the septum itself and produced bulging into the cavity of the right ventricle with obstruction of its outflow tract and signs of right ventricular failure.

\section{CASE REPORT}

Miss K., aged 59, had enjoyed good health save for one illness at the age of 49 when she had severe urticaria with vomiting for several weeks. She had no cardiac symptoms prior to April 5, 1946, when she felt sick, vomited, and had pain in the back between the shoulder blades. Pain persisted and she again vomited on April 9, on which day she first summoned Dr. McNab, who found no abnormality of her heart or lungs. She remained in bed for a week and during the next ten days she was up, going about slowly; her pain had subsided and she seemed convalescent. On April 26, she suddenly became breathless but did not send for the doctor until the following day when he noted " extreme pallor, with systolic and diastolic murmurs that had not previously been present." From this time pallor persisted and breathlessness became more severe, but she had no further pain until the day of her death.

She was first seen by me on May 6, 1946. She was of average nutrition with grey complexion, pale cyanosed lips, pale conjunctivæ, and breathlessness. The jugular veins were distended and there was lumbar œdema. The liver was enlarged, extending $4 \mathrm{~cm}$. below the costal margin. The tongue was dry and furred; a faint smell of acetone was noted from the breath. Coarse rales were present over a limited area at the base of each lung. The pulse was of very poor quality, barely perceptible, and it was impossible to obtain a blood pressure reading. The heart rate was 96. A feeble cardiac impulse could be felt, but there was no thrill; the apex was $11 \mathrm{~cm}$. from the midline, and the percussion dullness was increased both to right and to left. The first heart sound was totally obscured by a loud blowing murmur which contrasted sharply with the feeble impulse and barely perceptible pulse; the murmur was heard over a very wide area both in the front and back of the chest; its intensity was maximal along a 


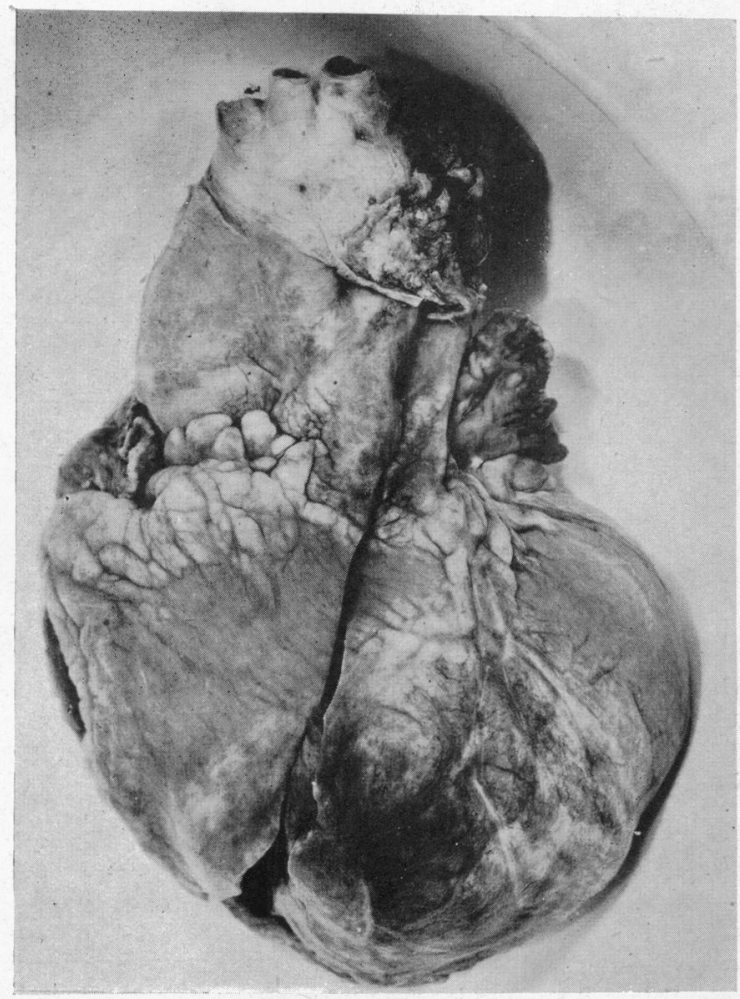

Fig. 1.-Anterior surface of the heart, showing discoloured swollen area produced by the septal dissecting aneurysm. Along the left border just above the apex, an area of slight bulging corresponding to an earlier myocardial infarct can be seen.

line joining the fourth left chondro-sternal junction to the apex. The second heart sound was inaudible and no diastolic murmur could be heard.

The patient was admitted to hospital immediately. Following admission she had several bouts of coughing with small hæmoptyses. Her condition deteriorated and she died 33 hours later. A cardiogram showed a Pardee curve of Q I, T I type with a small detached Q I, slightly elevated R-T I, small terminal inverted $T$ I, and slightly negative R-T III. A portable X-ray suggested enlargement of the heart both to left and to right; the superior vena caval shadow was prominent and there was moderate congestion of the lung fields.

Post-mortem Examination (Dr. J. Adler). The pericardium contained $35 \mathrm{ml}$. of straw-coloured fluid.

The heart weighed $460 \mathrm{~g}$. On the anterior surface

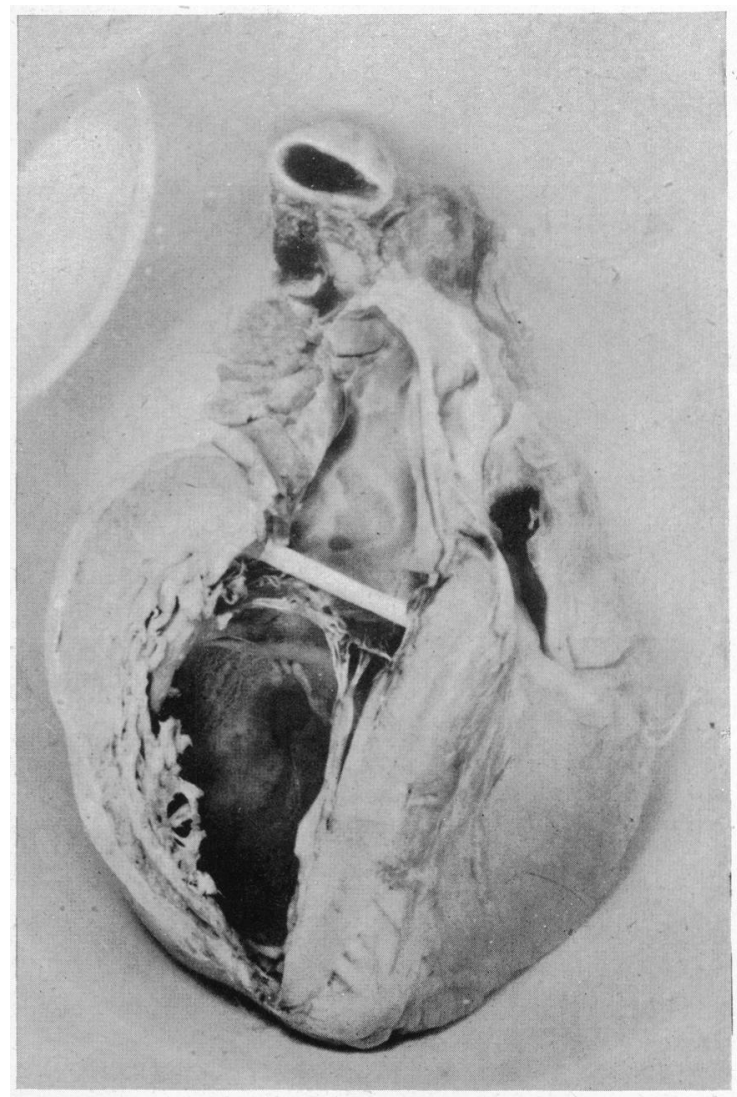

FIG. 2.-Interior of the left ventricle and septum viewed from the left, showing lamellated thrombus on the septum, perforation with everted upper lip, hypertrophy of left ventricle in its basal half, with fibrosis and thinning of the wall in the apical portion.

near the apex was an area of discolouration and swelling (Fig. 1) measuring $55 \times 45 \mathrm{~mm}$., corresponding in position to the lower part of the interventricular septum and the apex of the right ventricle. To the left of this, a second area showed slight bulging without discolouration; the myocardium here was thin, clearly representing an old infarct scar with aneurysmal dilatation. Both areas were covered by a thin film of fibrin.

The wall of the left ventricle was hypertrophied, being $23 \mathrm{~mm}$. thick at its base; as it approached the apex it became thin, its thickness being reduced to $1.5 \mathrm{~mm}$. at one point; and here the myocardium was largely replaced by a fibrous scar. The apical half of the interventricular septum was covered by lamellated thrombus; the underlying septal myocardium was necrotic. In the upper and anterior part of the septum there was a round perforation 


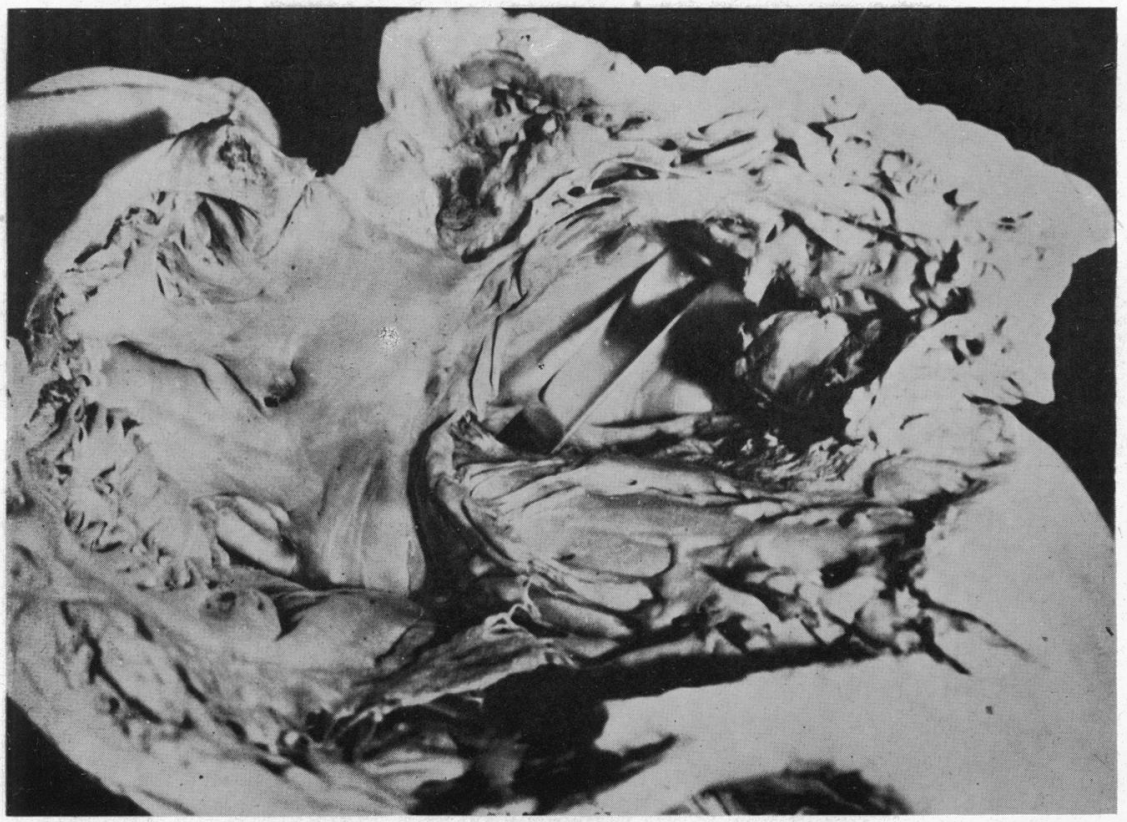

Fig. 3.-Interior of right auricle and ventricle, photographed from the right and below, so as to look into the pulmonary conus across which a glass rod has been placed. The projecting portion of the septal aneurysm is seen on the right of the photograph, at the junction of the septum with the reflected anterior wall of the ventricle. The photograph was made two years after the original examination of the specimen, at which time the aneurysm was opened; considerable shrinkage of the swelling occurred in the interval.

$10 \mathrm{~mm}$. in diameter; its upper lip was irregular, ragged, and everted so as to project into the cavity of the ventricle as a small flap (Fig. 2). The perforation led into a dissecting aneurysm of the septum; after running forwards and towards the right till separated from the right ventricular cavity by a layer of tissue only $1 \mathrm{~mm}$. thick, it tracked downwards and forwards towards the apex and anterior wall of the right ventricle. Where it emerged from the septum into the anterior wall of the ventricle, it produced the area of swelling and discolouration seen on the surface (see Fig. 4).

The tissue separating the cavity of the aneurysm from that of the right ventricle consisted of endocardium with a thin layer of intact myocardium. Viewed from the right ventricle, the aneurysm formed an irregularly oval swelling measuring $38 \times 28 \mathrm{~mm}$., and projecting into the cavity of the ventricle to a depth of $15 \mathrm{~mm}$. (Fig. 3). This was situated at the junction of the septum with the anterior wall of the ventricle, being so placed as to project into the proximal half of the outflow tract. On opening the aneurysm from the right side it was found to be partly filled by organizing thrombus.
The right ventricle was distended, but not much hypertrophied. A small amount of adherent thrombus was present at its apex (Fig. 4).

All valve cusps were healthy. The right coronary artery was calcified along its entire length but was patent. The anterior descending branch of the left coronary artery was the seat of extensive calcification; the vessel was much reduced in calibre throughout its length, and it was occluded by a thrombus at a point $2 \mathrm{~cm}$. from its origin. The circumflex branch of the left coronary artery showed patchy atheromatous calcification.

Calcification was present also in the arteries at the base of the brain. The kidneys showed fibrosis and hyalinization of some glomeruli. The lungs were chronically congested with several recent hæmorrhagic infarcts in each lower lobe. Each pleural cavity contained $200 \mathrm{ml}$. of fluid. The remaining organs were congested.

\section{Discussion AND Summary}

Post-mortem examination showed both old and recent myocardial infarcts. The earlier infarct had 


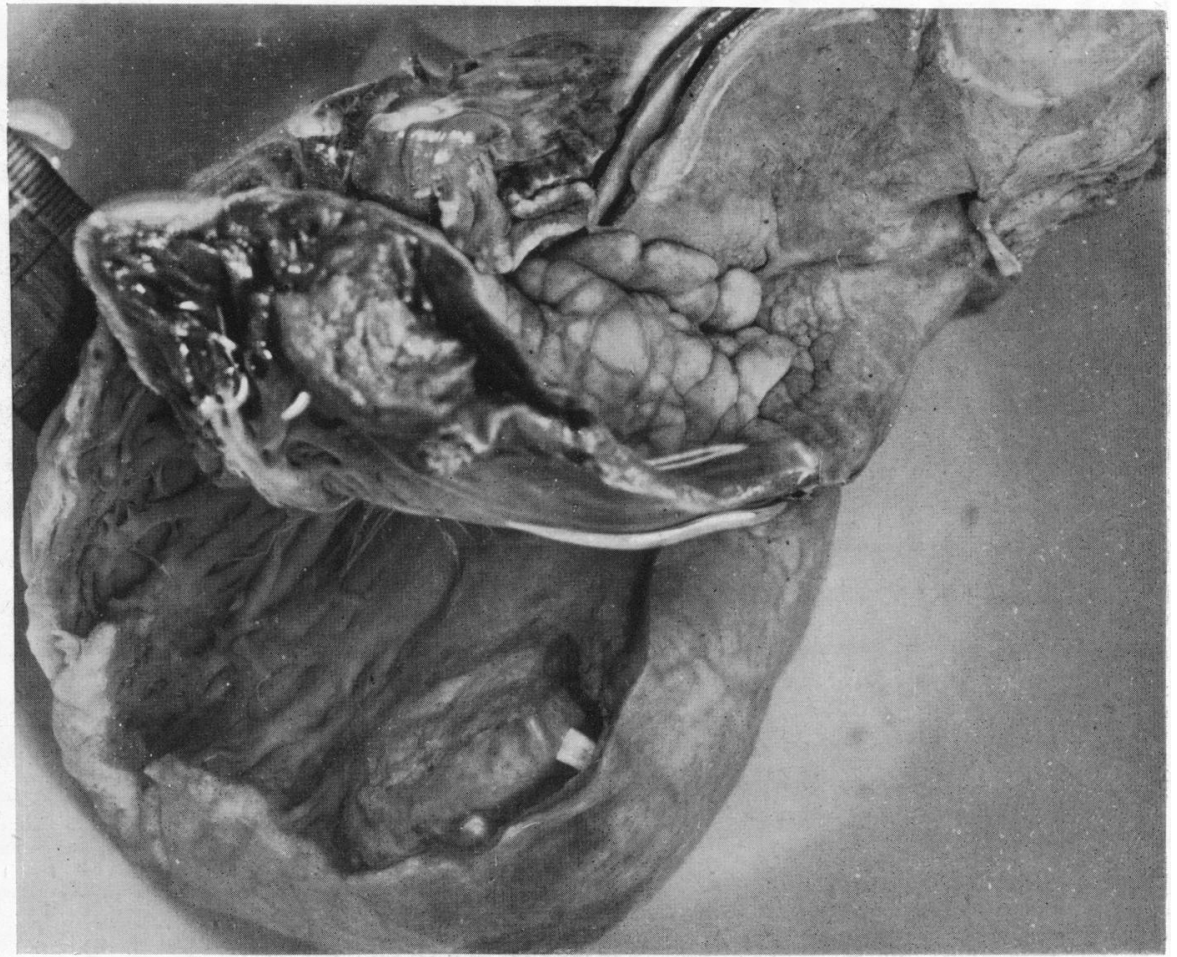

FIG. 4.-Interior of the right ventricle which has been opened along the junction of its anterior wall with the septum; in so doing the aneurysm has been cut through and a portion has been turned back with the anterior wall. The cavity is approximately two-thirds filled with adherent thrombus; its relation to the area of surface discolouration is shown.

affected the left ventricle near the apex producing aneurysmal dilatation of the affected area. This lesion was certainly of some years' standing. Despite the aneurysmal dilatation that followed the initial infarct in a woman who had clearly been hypertensive, there was no admission of incapacity or disability; and the patient's only previous illness did not suggest cardiac disease.

The more recent coronary occlusion gave rise to infarction of the septum and appeared to correspond to the onset of her final illness on April 5, 1946. It was not associated with præcordial or substernal pain but with pain in the back. Perforation into the septum occurred on the twenty-first day; it was associated with sudden breathlessness, pallor, and appearance of a bruit de Roger; there was no thrill. The murmur, which clinically resembled that heard with a congenital ventricular septal defect, is difficult to explain in the absence of a "through and through" perforation. Two possible mechanisms suggest themselves; the everted upper lip of the perforation might have produced such a murmur; alternatively, it may have arisen in the right ventricle from slackening of the chordæ tendineæ and tricuspid curtain, consequent on displacement of the papillary muscle by the aneurysm. The subsequent features of the illness were those of progressive right ventricular failure, coupled with signs suggesting a low cardiac output; they are attributed in part to mechanical obstruction of the outflow tract of the right ventricle by protrusion of the septal aneurysm into it, and in part, to disease of the myocardium. The clinical picture was further complicated by the occurrence of terminal lung infarcts. Death took place on the twelfth day after the rupture.

The fact that rupture in this case led to a dissecting aneurysm instead of a "through and through" perforation, seems to be related to the survival of a thin layer of myocardium immediately beneath the endocardium of the right ventricle; the aneurysm tracked along the line of demarcation between necrotic and intact muscle. 


\section{REFERENCES}

Bernheim (1910). Rev. Médecine, 30, 785.

(1915). J. de Practiciens, Nov. 13, quoted from Glushein and Geer (1944).

Bullrich, R. A. (1927). Rev. méd. lat.-amer., 12, 31. (1928). Ibid. 13, 1839.

Fishberg, A. M. (1937). Heart Failure, London, p. 432.

Glushein, A. S., and Geer, J. A. (1944). M. Bull. vet. Admin., 20, 277.
Laubry, C. (1924). Bull. Mém. Soc. méd. Hôp. Paris, 48, 831 .

Martini, T., and Joselwick, M. (1927). Sem. med., 34 (11), 11.

Patiro-Mayer, C., and Mazzei, E. S. (1928). Rev. méd. lat.-amer., 13, 2015.

Russek, H. I., and Zohman, B. L. (1945). Amer. Heart J., 30, 427.

Wood, Änne M. (1944). Brit. Heart J., 6, 191. 